\title{
Transcatheter closure of a residual shunt with posteroinferior deficient rim after surgical closure of an ASD: a case report
}

\author{
Xicheng Deng ${ }^{1 *} \mathbb{D}$, Taoyue Yao ${ }^{2}$, Yefeng Wang ${ }^{1}$, Guangxian Yang ${ }^{1}$, Wenjuan Chen², Peng Huang ${ }^{1}$ and Zhi Chen ${ }^{1}$
}

\begin{abstract}
Background: There are few reports in the literature of device closure of residual shunts following initial surgical closure of an atrial septal defect (ASD). This case study reports one such case. We describe here a case of secundum type ASD that was initially closed surgically, followed by device closure of a residual shunt with a posteroinferior deficient rim.

Case presentation: A 7-month-old boy was admitted to our hospital for elective surgery to surgically correct a secundum type ASD. Unfortunately, a residual shunt $3.5 \mathrm{~mm}$ in diameter appeared before discharge and was enlarged at1-year follow-up. The cause of this residual shunt was dehiscence at the posteroinferior aspect, and the posteroinferior rim was $3.7 \mathrm{~mm}$. After careful discussion and preparation, we proceeded with an interventional procedure. A $16 \mathrm{~mm}$ ASD occluder (AGA Medical Corp, Plymouth, Minnesota) was deployed successfully with no residual shunt. In some cases of ASD, interventional therapy is not considered due to the size and position of the defect, but we show here, a successful case of interventional therapy for a residual shunt with a deficient rim.
\end{abstract}

Conclusion: We have presented a case in which a postoperative residual shunt with a deficient rim was successfully closed with interventional therapy.

Keywords: Case report, Atrial septal defect, Residual shunt, Interventional, Postoperative

\section{Background}

Secundum type atrial septal defect (ASD) is a common congenital heart defect [1] and interventional device occlusion is the treatment of choice as techniques and devices for transcatheter treatment have been evolved and refined [2-4]. Though generally it is acknowledged in children, transcatheter closure should be reserved for patients older than 2 years and with weight $>15 \mathrm{~kg}[5,6]$, studies have shown less than $10 \mathrm{~kg}$ is also safe and effective in experienced hands with excellent early results

\footnotetext{
*Correspondence: justindxc@gmail.com

All authors take responsibility for all aspects of the reliability and freedom from bias of the data presented and their discussed interpretation ${ }^{1}$ Heart Center, Hunan Children's Hospital, Changsha 410007, China Full list of author information is available at the end of the article
}

$[7,8]$. The alternative to transcatheter treatment is surgical repair with an antilogous pericardial or synthetic patch. Reports have been published with regard to residual shunts after surgical or interventional therapy and their treatment $[9,10]$. Most residual shunts have sufficient rims to be closed with an occluder and few reports device closure of residual shunts following initial surgical closure of an atrial septal defect (ASD).

\section{Case presentation}

A 7-month-old boy weighing $7 \mathrm{~kg}$ was admitted to our hospital for elective surgery to correct a secundum type ASD. The defect had been suspected during physical examination for pneumonia and was confirmed with an echocardiography previously at 4-month-old. Though he had been generally well and without tachypnea, 
tachycardia or cyanosis, etc., the pneumonia could not be ruled out to have had an association with this large ASD. The patient's past medical and surgical histories were non-significant. The boy's nutritional status and physical development were normal. He was born via C-section at 36 weeksplus1day gestation weighing $2.4 \mathrm{~kg}$. While the mother experienced low amniotic fluid during pregnancy, there were no signs of intrauterine distress or asphyxia during pregnancy and delivery.

The patient's cardiac status on admission was assessed as New York Heart Association Class II (mild symptoms). Respiratory rate was 28 breaths per minute, heart rate was 122 beats per minute with sinus rhythm, and blood pressure was10.8/5.2 $\mathrm{kPa}$. On auscultation, a II/6 gentle systolic murmur was heard at the left sternal border between the second and third intercostal space.

Blood tests indicated slight microcytic hypochromic anemia (mean corpuscular volume $76.0 \mathrm{fL}$, hemoglobin $108.0 \mathrm{~g} / \mathrm{L}$, and mildly elevated aspartate aminotransferase $58.5 \mathrm{IU} / \mathrm{L}$. Other values were normal. A preoperative echocardiography suggested the presence of a $15 \mathrm{~mm}$ by $10 \mathrm{~mm}$ secundum ASD (Fig. 1a), deemed quite large for a 7 months old baby. With only a $3.7 \mathrm{~mm}$ rim in the posteroinferior aspect, which is generally considered not amenable to cath-lab procedure. And the right heart was also shown enlarged significantly under echocardiography. Though we do not routinely measure Qp:Qs with echocardiography or perform a catheter procedure for an ASD to measure it, the signs under echocardiography indicated surgery as necessary.

At our institution, 600 open-heart cases per year were performed. Our surgeons are experienced with and confident in infants or even neonate with complex defects, so ASD repair within infancy dose not bring higher mortality or morbidity. The rationale of repair a large ASD is to avoid negative impact on growth and development that may occur if surgery is refrained until beyond infancy. Elective open-heart surgery was performed, and it was confirmed during surgery that the posteroinferior rim was insufficient for cath-lab procedure. The defect was therefore closed with an autologous pericardial patch; the procedure was straightforward. Transesophageal echocardiography confirmed that there was no residual shunt through the defect before the patient was weaned from cardiopulmonary bypass. However, the predischarge echocardiogram on postoperative day 5 suggested a3.5 mm-diameter shunt in the middle portion of the interatrial septum. Since it was small, followup was suggested. Follow-up echocardiograms at 1 month and 3 months showed the shunt to be $5-6 \mathrm{~mm}$ in diameter, and showed slight right cardiomegaly (Fig. 1b \& c).
At 1-year follow-up, when the patient was 1 year and 7 months old and weighed $10 \mathrm{~kg}$, an echocardiography suggested the shunt was further enlarged to $8 \mathrm{~mm}$, and the right cardiomegaly had become moderate (Fig. 1d). After careful discussion and preparation, we proceeded with an interventional procedure, with open-heart surgery planned as a backup. An additional echocardiography in the cardiac catheterization lab revealed two residual shunts of $9 \mathrm{~mm}$ and $4 \mathrm{~mm}$ diameter, and the pulmonary and systemic blood flow ratio was 1.8 as measured by right cardiac catheterization. A16 mm ASD occluder (AGA Medical Corp, Plymouth, Minnesota) was deployed successfully without any residual shunt (Figs. 1e \& 2).

The 3-month postoperative follow-up showed that the patient was doing well, with the occluder in its proper position and no sign of any residual shunt under echocardiography (Fig. 1f).

\section{Discussion}

Atrial septal defect is a common type of congenital heart disease, of which the secundum type is the most common. Cath-lab procedure with an occluder to close the defect is the standard treatment, provided there are sufficient rims around the defect and the sizes of the defects are appropriate [11]. If the rim is less than $5 \mathrm{~mm}$ in any aspect, it is deemed deficient and cath-lab procedure is not recommended [12], as rim deficiency is associated with significantly lower success rates $[13,14]$. In this case, open-heart surgery and surgical repair of the defect may have to be chosen. Mortality and morbidity are low in the treatment of this condition, regardless of which approach is chosen $[15,16]$. Some publications have reported a second device closure for residual shunt following initial transcatheter closure $[10,17,18]$ or surgical treatment for residual shunt after transcatheter closure [19]. However, reports of cath-lab procedure to close a residual shunt following initial surgical closure of ASD are rare $[20,21]$.

In our case, open-heart surgery was performed because the posteroinferior rim, at $3.7 \mathrm{~mm}$, was insufficient for transcatheter closure to be considered feasible. Since the intraoperative transesophageal echocardiography showed no residual shunt, but a shunt was detected on postoperative day 5 before discharge, it was strongly suspected that the newly detected shunt was due to suture dehiscence. For a defect with a deficient posteroinferior rim, the most likely site for dehiscence was close to the posteroinferior rim $[22,23]$. This was confirmed by the final echocardiography at 1-year follow-up before residual shunt closure. The same echocardiography confirmed firm attachment of the patch to the atrial septum, with no apparent free movement of the patch. Cath-lab procedure to close the residual shunt with an 


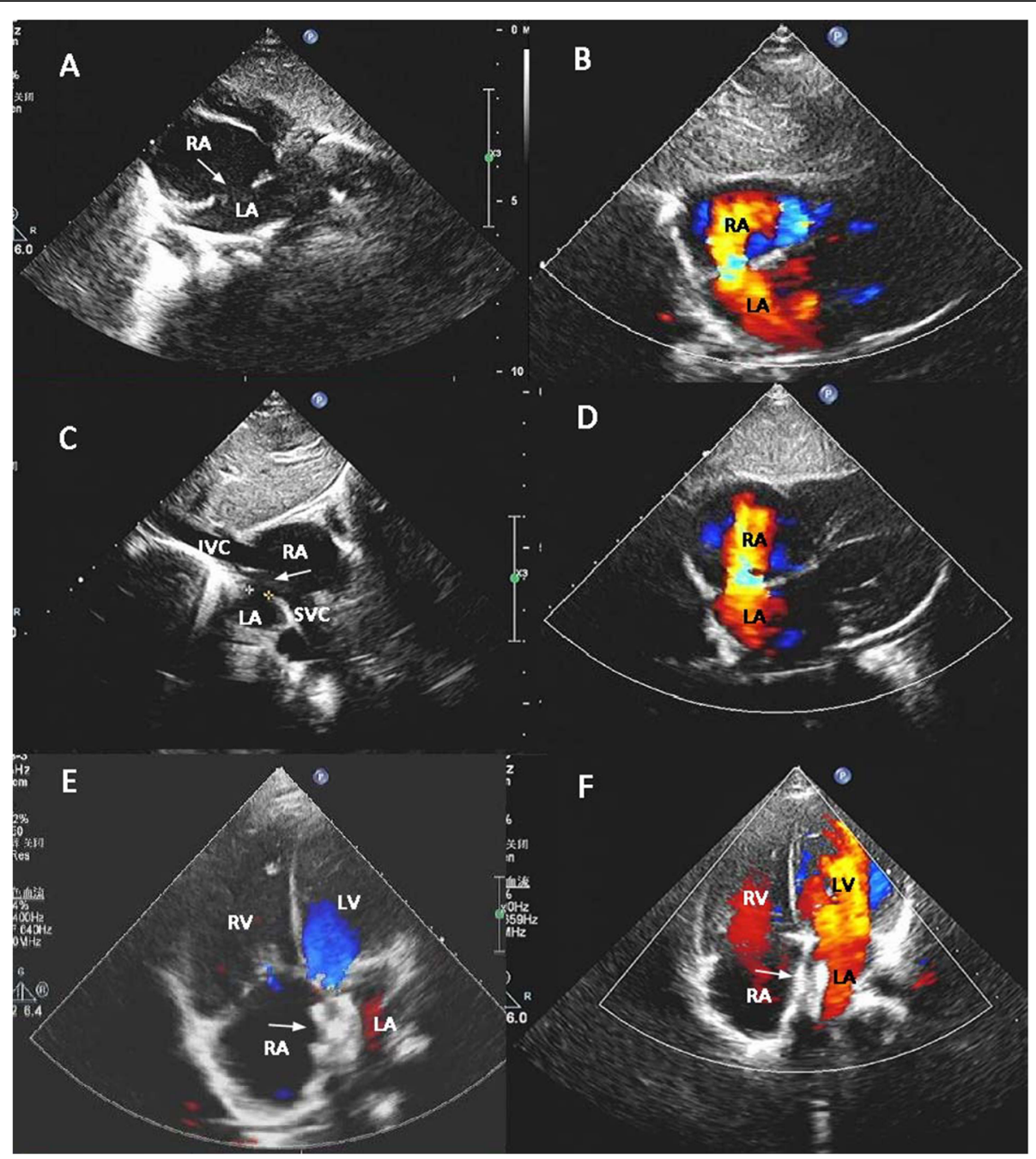

Fig. 1 a Preoperative echocardiography shows the ASD, the arrow showing the defect; $\mathbf{b}$ The residual shunt 1 month after initial surgery. The red circle indicates the deficient posteroinferior rim; c Bicaval view of the residual shunt 3 months after initial surgery, the arrow showing the defect with minimum rim in the posteroinferior aspect; $\mathbf{d}$ The residual shunt 1 year after initial surgery; e Device closure of the residual shunt, the arrow showing the occluder. $L A=$ left atrium; $L V=$ left ventricle; $\mathbf{f}$ Three months after device closure of the residual shunt, the arrow showing the occluder. $\mathrm{LA}=$ left atrium, LV = left ventricle, $\mathrm{A}$ = right atrium, $\mathrm{RV}=$ right ventricle, IVC = posteroinferior vena cava, SVC= superior vena cava

occluder was planned. However, concerns remained about whether the tissue around the residual shunt was strong enough to hold an occluder in place. Moreover, the dehisced site was the posteroinferior aspect, which had been expected to have deficient rims. As such, we prepared for open-heart surgery as a backup. Our case has shown a residual shunt after surgery can be device-closed successfully even with a deficient rim in the posteroinferior aspect. This approach might be appropriate for other similar cases, including where a shunt has deficient rims in other aspects. Meticulous echocardiography examination should be carried out before any procedure. And a three-dimensional echocardiography may assist in decision-making or during transcatheter closure [2427] in such a case.

We should, however, carefully interpret this case. As the residual shunt was smaller than the initial size of the defect and they had different configuration in terms of the aspects of the rim, the residual defect being deviceclosed successfully does not necessarily mean initially the ASD could be device-closed for sure, not even considering the lower weight in the initial operation. If we had the chance to do it again, we may try in a one-stop way to do it percutaneously with open heart surgery as a back-up. This should be discussed in the cardiac team on a case by case basis, accounting for patient's age, weight and size of the defect. 


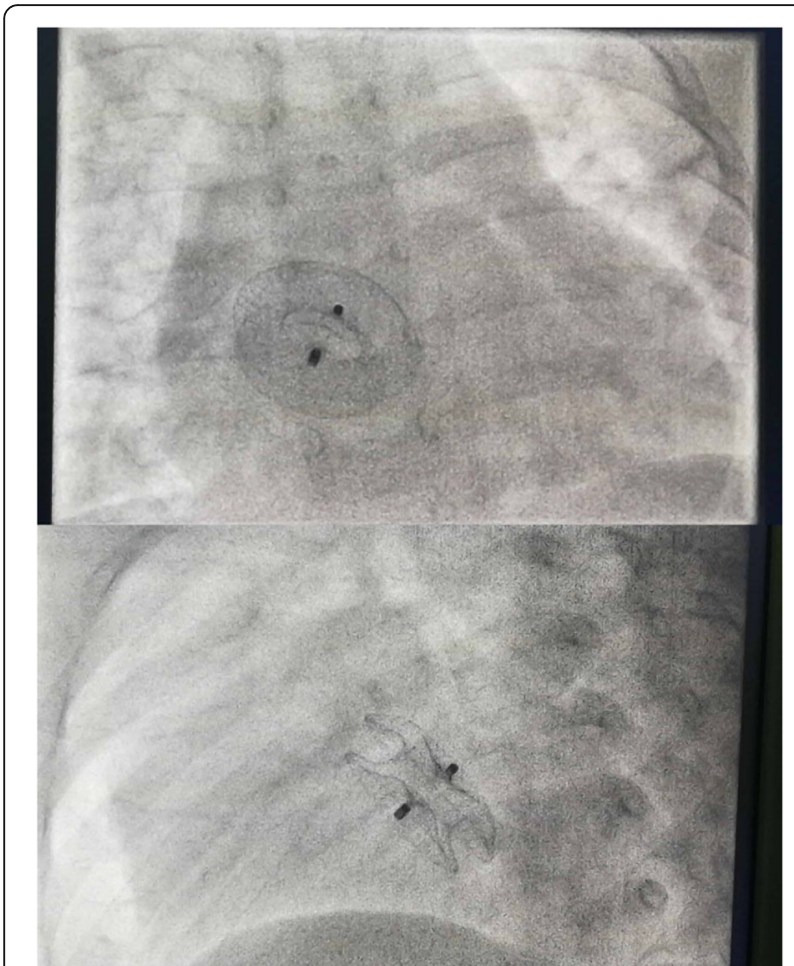

Fig. 2 Front (top) and lateral (bottom) views after the occluder was deployed under angiocardiogram

\section{Conclusions}

We have presented a case of a postoperative residual shunt with deficient rims being successfully closed with cath-lab procedure, which, in general, is considered not possible. Appropriate choice of treatment for a residual ASD should be carefully considered on a case-by-case basis after meticulous examination of a patient.

\section{Abbreviation}

ASD: Atrial septal defect

\section{Acknowledgements}

None.

\section{Authors' contributions}

All authors made substantial contributions to conception and design, or acquisition of data, or analysis and interpretation of data; XD, TY, GY, WC, PH, YW were involved in drafting the manuscript and revising it critically for important intellectual content; XD, ZC performed the surgical and interventional procedures. All authors read and approved the final version of the manuscript.

\section{Funding}

This project was supported by the Natural Science Foundation of Hunan Province, China (Grant No. 2019JJ80106) to XD to pay for article editing service and publication fee.

\section{Availability of data and materials}

All data generated or analyzed during this study are included in this published article.

Ethics approval and consent to participate Not applicable.

\section{Consent for publication}

Informed written consent was obtained from the patient's parents for publication of this report and any accompanying images.

\section{Competing interests}

The Authors declare that there is no competing interest.

\section{Author details}

${ }^{1}$ Heart Center, Hunan Children's Hospital, Changsha 410007, China. ${ }^{2}$ The Department of Ultrasound and Echocardiography, Hunan Children's Hospital, Changsha 410007, China.

Received: 29 May 2020 Accepted: 13 July 2020

Published online: 22 July 2020

\section{References}

1. Hoffman JI, Kaplan S. The incidence of congenital heart disease. J Am Coll Cardiol. 2002;39(12):1890-900.

2. Warnes CA, Williams RG, Bashore TM, Child JS, Connolly HM, Dearani JA, Del Nido P, Fasules JW, Graham TP Jr, Hijazi ZM, et al. ACC/AHA 2008 guidelines for the management of adults with congenital heart disease: a report of the American College of Cardiology/American Heart Association Task Force on Practice Guidelines (Writing Committee to Develop Guidelines on the Management of Adults With Congenital Heart Disease). Developed in Collaboration With the American Society of Echocardiography, Heart Rhythm Society, International Society for Adult Congenital Heart Disease, Society for Cardiovascular Angiography and Interventions, and Society of Thoracic Surgeons. J Am Coll Cardiol. 2008;52(23):e143-263.

3. Opotowsky AR, Landzberg MJ, Kimmel SE, Webb GD. Trends in the use of percutaneous closure of patent foramen ovale and atrial septal defect in adults, 1998-2004. JAMA. 2008;299(5):521-2.

4. Baumgartner H, Bonhoeffer P, De Groot NM, de Haan F, Deanfield JE, Galie N, Gatzoulis MA, Gohlke-Baerwolf C, Kaemmerer H, Kilner P, et al. ESC guidelines for the management of grown-up congenital heart disease (new version 2010). Eur Heart J. 2010;31 (23):2915-57.

5. Du ZD, Hijazi ZM, Kleinman CS, Silverman NH, Larntz K, Amplatzer I. Comparison between transcatheter and surgical closure of secundum atrial septal defect in children and adults: results of a multicenter nonrandomized trial. J Am Coll Cardiol. 2002;39(11):1836-44

6. Cowley CG, Lloyd TR, Bove EL, Gaffney D, Dietrich M, Rocchini AP. Comparison of results of closure of secundum atrial septal defect by surgery versus Amplatzer septal occluder. Am J Cardiol. 2001;88(5):589-91.

7. Ghaderian M, Sabri MR, Ahmadi AR, Dehghan B, Mahdavi C, Ataei ZZ. The efficacy and safety of using amplatzer for transcatheter closure of atrial septal defect in small children with less than $10 \mathrm{~kg}$. ARYA Atheroscler. 2019; 15(1):27-32.

8. Abu-Tair T, Wiethoff CM, Kehr J, Kuroczynski W, Kampmann C. Transcatheter closure of atrial septal defects using the GORE((R)) septal occluder in children less than $10 \mathrm{~kg}$ of body weight. Pediatr Cardiol. 2016;37(4):778-83.

9. Desnick SJ, Neal WA, Nicoloff DM, Moller JH. Residual right-to-left shunt following repair of atrial septal defect. Ann Thorac Surg. 1976;21(4):291-5.

10. Aguiar Rosa S, Ferreira F, de Sousa L, Fiarresga A, Martins JD, Galrinho A, Agapito A, Fazendas P, Pinto FF, Ferreira RC. Successful percutaneous closure of a residual atrial septal defect due to device failure. Rev Port Cardiol. 2017;36(6):475 e471-3.

11. Villablanca PA, Briston DA, Rodes-Cabau J, Briceno DF, Rao G, Aljoudi M, Shah AM, Mohananey D, Gupta T, Makkiya M, et al. Treatment options for the closure of secundum atrial septal defects: a systematic review and meta-analysis. Int J Cardiol. 2017;241:149-55.

12. Amedro P, Bayburt S, Assaidi A, Kreitmann B, Habib G, Fouilloux V, Fraisse A. Should transcatheter closure of atrial septal defects with inferior-posterior deficient rim still be attempted? J Thorac Dis. 2019;11(3):708-16.

13. Kijima Y, Akagi T, Takaya Y, Taniguchi M, Nakagawa K, Kusano K, Sano S, Ito $\mathrm{H}$. Deficient surrounding rims in patients undergoing transcatheter atrial septal defect closure. J Am Soc Echocardiogr. 2016;29(8):768-76.

14. Mulukutla V, Qureshi AM, Pignatelli R, Ing FF. Predictive factors for patients undergoing ASD device occlusion who "crossover" to surgery. Pediatr Cardiol. 2018;39(3):445-9.

15. Murphy JG, Gersh BJ, McGoon MD, Mair DD, Porter CJ, Istrup DM, McGoon DC, Puga FJ, Kirklin JW, Danielson GK. Long-term outcome after surgical 
repair of isolated atrial septal defect. Follow-up at 27 to 32 years. N Engl J Med. 1990;323(24):1645-50.

16. Butera G, Carminati M, Chessa M, Youssef R, Drago M, Giamberti A, Pome G, Bossone E, Frigiola A. Percutaneous versus surgical closure of secundum atrial septal defect: comparison of early results and complications. Am Heart J. 2006;151(1):228-34.

17. Man W, Xinxin M, Yueli Z, Feng L. Percutaneous closure of residual shunting in a patient with a fenestrated atrial septal defect occluder: a case report. Medicine (Baltimore). 2018;97(31):e11612.

18. Lopez AL, Palomas JL, Rubio DM, Ortiz MR. Three-dimensional echocardiography-guided repair of residual shunt after percutaneous atrial septal defect closure. Echocardiography. 2011;28(3):E64-7.

19. Berdat PA, Chatterjee T, Pfammatter JP, Windecker S, Meier B, Carrel T. Surgical management of complications after transcatheter closure of an atrial septal defect or patent foramen ovale. J Thorac Cardiovasc Surg. 2000; 120(6):1034-9.

20. Demir B, Tureli HO, Kutlu G, Karakaya O. Percutaneous closure of a postoperative residual atrial septal defect with the Occlutech Figulla Occluder device. Turk Kardiyol Dern Ars. 2012;40(1):55-8.

21. Chessa M, Butera G, Giamberti A, Bini RM, Carminati M. Transcatheter closure of residual atrial septal defects after surgical closure. J Interv Cardiol. 2002:15(3):187-9.

22. Cakal B, Cakal S, Arslan K, Kahveci G, Ozkan M. Dehiscence of an atrial septal defect patch: evaluation using three-dimensional transesophageal echocardiography. Herz. 2015;40(3):455-6.

23. Sivakumar K, Singhi A, Mohanraj A, Ezhilan J. Tumor embolism from a right atrial myxoma leads to acute right heart failure after surgery and atrial septal patch dehiscence. J Am Coll Cardiol. 2014;63(23):2579.

24. Jang JY, Heo R, Cho MS, Bae J, Hong JA, Lee S, Ahn JM, Park DW, Kim DH, Kang DH, et al. Efficacy of 3D transoesophageal echocardiography for transcatheter device closure of atrial septal defect without balloon sizing. Eur Heart J Cardiovasc Imaging. 2018;19(6):684-9.

25. Boon I, Vertongen K, Paelinck BP, Demulier L, Van Berendoncks A, De Maeyer C, Marchau F, Panzer J, Vandekerckhove K, De Wolf D. How to size ASDs for percutaneous closure. Pediatr Cardiol. 2018:39(1):168-75.

26. Ojala T, Rosenthal E, Nugent K, Qureshi S, Simpson J. Live 3D echocardiography to guide closure of residual ASD. J Am Coll Cardiol Img. 2013;6(4):523-5

27. Orvalho JS. Real-time three-dimensional echocardiography: from diagnosis to intervention. Pediatr Cardiol. 2017;47(5):1005-19.

\section{Publisher's Note}

Springer Nature remains neutral with regard to jurisdictional claims in published maps and institutional affiliations.

Ready to submit your research? Choose BMC and benefit from:

- fast, convenient online submission

- thorough peer review by experienced researchers in your field

- rapid publication on acceptance

- support for research data, including large and complex data types

- gold Open Access which fosters wider collaboration and increased citations

- maximum visibility for your research: over $100 \mathrm{M}$ website views per year

At $\mathrm{BMC}$, research is always in progress.

Learn more biomedcentral.com/submissions 